\title{
The Development and Clinical Implication of Subconcept of Death in Children
}

\author{
Geon Ho Bahn ${ }^{1}$, Eun-Jin Park², So Hee Lee ${ }^{3}$, Ram Hwangbo ${ }^{4}$, and Seongwoo Cho ${ }^{4}$ \\ 'Department of Psychiatry, Kyung Hee University School of Medicine, Seoul, Korea \\ 2Department of Psychiatry, College of Medicine, Inje University, Ilsan Paik Hospital, Ilsan, Korea \\ ${ }^{3}$ Department of Psychiatry, National Medical Center, Seoul, Korea \\ ${ }^{4}$ Department of Psychiatry, Graduate School, Kyung Hee University, Seoul, Korea
}

\section{소아에서 죽음의 하위 개념 발달과 임상적 의의}

\author{
반건호 ${ }^{1} \cdot$ 박은진 $^{2} \cdot$ 이소희 ${ }^{3} \cdot$ 황보람 $^{4} \cdot$ 조성우 ${ }^{4}$ \\ 경희대학교 의학전문대학원 정신건강의학교실, ${ }^{1}$ 인제대학교 의과대학 일산백병원 정신건강의학교실, ${ }^{2}$ \\ 국립의료원 정신건강의학과, ${ }^{3}$ 경희대학교 대학원 정신건강의학교실 ${ }^{4}$
}

\begin{abstract}
Although children and adolescents sometimes experience death of a family member or pet, it is difficult for them to comprehend death as a part of life process. The manner in which children understand the concept of death is unclear. In this study, we attempted to analyze and determine the understanding of the concept of death in children. Subconcepts like irreversibility, non-functionality, inevitability or universality, causality, etc., develop sequentially during childhood. Some argue that other subconcepts like non-corporeal continuation, unpredictability, and old age also develop during that period. The concept of the death itself is limited, and the debate continues on whether it is ethical to perform related research on children. However, it is very important to assess how children think about and react to death clinically, as well as to find ways to help them when necessary. It is important to understand the emotional reaction and progression including depression and anxiety that results from the death of loved ones, like parents. Because the ability to understand and accept death develops with age, it is necessary to develop a method that can improve the child's ability to understand death according to their age. Such method will allow children to overcome the death of loved ones and reinvest in their life after going through a sufficient period of mourning.
\end{abstract}

Psychoanalysis 2016;27(3):92-100

KEY WORDS: Subconcept $\cdot$ Death $\cdot$ Suicide $\cdot$ Family $\cdot$ Childhood $\cdot$ Irreversibility $\cdot$ Depression.

Received: June 16, 2016 Revised: July 4, 2016 Accepted: July 4, 2016

Address for correspondence: Geon Ho Bahn, MD

Department of Psychiatry, Kyung Hee University School of Medicine, 23 Kyungheedae-ro, Dongdaemun-gu, Seoul 02447, Korea

Tel: +82-2-958-8542, Fax: +82-2-957-1997, E-mail: mompeian@khu.ac.kr

\section{서 론}

소아가 죽음을 어떻게 인식하고 있는가에 대한 최초의 구 체적 연구는 Schilder와 Wechsler(1934)가 발표한 '죽음에 대한 어린이의 태도(the attitude of children toward death)' 라는 논문에서 시작되었다. 당시 유럽에 확산되고 있었던 정 신분석의 창시자인 Sigmund Freud가 주장한 죽음 본능 (death instinct)(Gay 2006)과 실제 죽음과의 관련성을 밝히

This is an Open Access article distributed under the terms of the Creative Commons Attribution Non-Commercial License (http://creativecommons.org/licenses/by-nc/3.0) which permits unrestricted non-commercial use, distribution, and reproduction in any medium, provided the original work is properly cited.
기 위한 연구였다. 이 논문에서는 5 세에서 15 세 사이의 소아 76 명을 대상으로 죽음과 관련된 사진 여덟 장을 보여 주고 아이들이 묘사한 내용을 분석하였다. 이 논문에서는 소아의 죽음에 관한 인식은 박탈의 개념에서부터 시작됨을 밝혔다. $\operatorname{Nagy}$ (1948)는 죽음에 관한 세 가지 하위 개념(universality, irreversibility, finality)에 대하여 서술하였고, Childers와 Wim$\operatorname{mer}(1971)$ 는 6세에서 9세까지의 소아를 대상으로 죽음의 또 다른 하위 개념으로 universality와 irreversibility에 관하여 연구하였다. 이후 연구에서는 소아가 보편성(universality)을 비가역성(irreversibility)과 최종적임(finality)에 비하여 더 잘 이해한다고 보고하였다(White 등 1978). 이차대전 당시 Hampstead 보육원을 운영한 Anna Freud 역시 아이들의 죽 
음 인식에 관심을 가졌다(Freud 1973). 평화 시에는 아이들에 게 '죽는다'는 것이 어디론가 '가는 것'이었으나, 아이들이 전 쟁을 겪으며 부모나 주변 인물들의 실종과 죽음을 자주 경 험하다 보면 어느 순간 갑자기 '죽음'을 알게 되는 것 같다고 하였다. 이와 비슷한 연구로 죽음에 관한 10 가지 구성개념, 즉 현실성(realization), 이별(separation), 움직일 수 없음(immobility), 비가역성, 인과성(causality), 기능부전(dysfunctionlity), 보편성, 무감각(insensitivity), 출현(appearance), 의인 화(personification)를 이용하여 가까운 주변인이 사망한 경 험이 있는 소아들이 없는 소아들에 비해 모든 구성개념의 이 해도가 높다는 것을 알아냈다(Kane 1979). 소아기 죽음의 이 해라는 주제는 관심 있는 주제임에는 틀림없으나 연구 기법의 한계와 대상이 소아라는 제약 때문에 1980년대까지도 관련 연구가 활성화되지는 못하였다(Lazar와 Torney-Purta 1991). 그러나 1966 1968년 기간 동안 소식지(newsletter) 형태로 발행되던 Omega가 1970년부터 '오메가: 죽음 및 죽어가는 것(Omega: death and dying)'이라는 공식 학술지로 출간되면 서 자살 연구가 활발해지는 계기가 되었다(Fulton 등 2014 2015).

그렇듯 정신분석학적 개념에서 출발한 '죽음' 관련 연구는 텔레비전을 비롯한 다양한 미디어가 개발되면서 개인과 가 족의 문제로부터 사회적 경험을 통해 영향 받는 주제로 확대 되었다(Lazar와 Torney-Purta 1991). 대표적인 것이 1986년 미국의 우주왕복선인 챌린저호 폭발사고였다. 미국인의 $17 \%$ 가 지켜본 발사 장면과 발사 후 약 73 초 만에 폭발되어 일곱 명의 우주인이 사망한 사건은 이를 지켜본 모든 이에게 영향을 미쳤다. 죽음의 과정을 중계한 것이다. 이 폭발과 관 련된 '외상 후 스트레스장애'의 연구가 장기간 진행되었다 (Terr 1991). 이후에도 엄청난 대형 재난이 미디어를 통해 대 중에게 전달되었으며, 그 파장을 평가하고 대책을 세우는 데 많 은 노력과 시간이 소요되었다. 2000년 발생한 미국의 $9 \cdot 11$ 테러(Rousseau 등 2015)나 우리나라의 세월호 사건이 대표 적이다(Han 등 2016). 세월호의 경우 몇 시간 동안 배가 침 몰되는 것을 텔레비전에서 중계하였고, 사건 후에도 오랜 기 간 제대로 마무리가 되지 않으면서 '사망자'에 대한 언급이 계속되고 있다. 소아청소년을 죽음에 노출시키는 또 하나의 주요 과제는 우리나라의 높은 자살률이다(Jeon 등 2013).

이처럼 죽음이라는 주제는 소아의 생활 속에 밀접하게 연 결되어 있으나, 실제로 구체적인 연구 자료는 많지 않다. '죽 음'이라는 주제 자체가 접근하기 어렵고, 더구나 소아를 대 상으로 연구하기는 쉽지 않다(Lazar와 Torney-Purta 1991). 그러나 5 7세 소아들을 대상으로 죽음의 이해 정도를 평가 한 최근 연구에서는 부모들이 생각하고 있는 것보다 아이들
은 죽음의 비가역성, 인과성, 비기능성 개념을 더 정확하게 알고 있었고, 여자 아이들은 보편성 개념에 대해서도 정확히 알고 있었다(Gaab 등 2013). 부모는 자녀들과 죽음에 대해 이야기하는 것을 꺼리지만, 건강한 아이들에게 죽음에 대해 생각해 보았느냐는 질문에 83\%가 그렇다고 대답한 경우도 있다(Perrin과 Gerrity 1981). 심각한 만성 질병을 않고 있는 아이들의 경우, 병원에 자주 입원하거나 죽음을 목격할 기회 가 많아지면서 죽음의 의학적 및 생물학적 영역에 대한 이 해가 또래 아이들에 비해 촉진되기도 한다(Slaughter 2005).

피할 수 없고 확인해야만 하는 주제이기에 본 논문에서는 현재까지 진행된 소아의 죽음 개념에 대한 이해 연구, 가족 구성원의 죽음이 아이에게 미치는 정신의학적 영향 및 아이 에게 죽음을 이해시키는 기법에 대해 문헌을 검토하였다.

\section{본 론}

\section{소아의 죽음 이해에 대한 초창기 정신분석적 접근}

1910년 Alfred Adler가 비엔나정신분석학회에서 자살관 련 학술대회를 주관하는 과정에서 당시 유럽에서 늘고 있던 학생들의 자살에 대한 주제가 발표된 바 있으나, 이후 관련 연구는 이어지지 못하였다(Shneidman 1969). 초창기 죽음 관련 연구는 정신분석 이론을 배경으로 한 접근이었다 $(\mathrm{Br}-$ omberg와 Schilder 1933). Freud가 죽음 본능(death instinct)에 의한 자기 파괴적 행위에 대해 언급하기는 하였으나 구체적 연관성을 제시하지는 못하였다(Gay 2006). 죽음에 관 한 초기 연구의 하나는 76 명의 정상 성인을 대상으로 한 죽음 관련 주제에 대한 면담 결과 연구였다(Bromberg와 Schilder 1933). 성인 연구 이후 5 15세 사이 소아청소년에게 죽음 관 련 그림을 보여 주고 반응을 분석하였다(Schilder와 Wechsler 1934). 질문 내용은 성인 연구에서 하였던 것을 소아청소 년 수준에 맞춰 바꿨다. 특이한 점은 성인 연구에서는 정상 집단이 대상이었으나, 소아 연구의 대상은 대부분 행동문제 가 있는 아이들이었다. 일부 대상 아동은 뇌염 등 기질적 원 인에 의한 과다행동장애, 간질, 정신적 결함(mental defective, 오늘날 개념은 지적장애)을 가지고 있었다. 이 연구 결과를 토대로 새로운 이론을 정립하지는 못하였으나, 오늘날 소아 의 죽음 관련 연구의 효시가 되었다. 흥미로운 점은 대상 아동 중 네 명이 죽고 싶다는 생각(자살사고)을 말로 표현하였다 는 점이다. 열 살과 열 다섯 살짜리도 있었고, 6세 아동도 있 었다. 이 아동의 부모가 짧은 기간 동안 연속으로 사망하였 고, 아이도 우울증 치료를 받았다.

초기 연구에서는 소아의 죽음에 대한 개념 발달을 세 단계 로 보았다(Nagy 1948). 3세에서 5세 사이의 소아는 죽음이 생 
의 연속성이 사라지는 것이며, 덜 깨어 있거나 매우 졸린 상태 로 보며 잠시 뒤에도 깨어나지 않는 상태로 본다. 5세에서 9 세 소아는 죽음을 의인화하여 저승사자가 목숨을 빼앗아 간 사람들만 죽는다고 생각한다. 드물게 죽음을 죽은 사람과 동 일한 개념으로 생각하기도 하지만, 보편화 시키지 않고, 자신 과는 거리가 먼 일이며 똑똑하거나 운이 좋으면 죽음으로부 터 벗어날 수 있다고 생각한다. 9세 이후의 소아는 죽음이 단 지 마지막이 아니라 불가피하고, 보편적이고 개인적이라고 본다. 즉, 사람은 똑똑하거나 운이 좋은 것과 관계 없이, 모두 죽는다는 것을 이해한다.

정신분석적 접근에서는 두 가지 특징이 있다(Kane 1979). 하나는 일반적인 예상과 크게 다르지 않다. 즉, 죽음이란 아 이들에게 정서적 반응과 관련된 주제로서, 슬픔, 불안, 분리 에 대한 두려움 등을 동반한다. 다른 하나는 어른들의 예상과 차이가 있었다. 열 살 또래 아이들은 사람이 죽으면 천국이나 죽은 이들을 위해 지정된 특별한 어떤 곳으로 가는 것으로 알 고 있었다. 인지적 및 정서적 미성숙에 의한 이해의 한계 때 문이다.

\section{Piaget 인지이론에 근거한 연구}

1960년대 들어 정서적 측면 이외에 Piaget의 인지발달 이 론에 근거한 연구가 활성화되었다(Slaughter 2005). 2 7세 소아는 Piaget 이론의 전조작기(preoperational period)에 해 당하며, 이 시기 아이들에게 죽음은 일시적 또는 되돌릴 수 있는 것이며, 잠깐 조용히 있거나 눈을 감고 있는 것 또는 어 디론가 떠난 것이다. 7 11세 소아는 구체적 조작기(concrete operational period)로, 이 시기에는 모든 생명체는 반드시 죽고, 되돌릴 수 없는 상태임을 알게 된다. 그러나 죽음의 원 인이 신체 외부에서 온다고 생각하며, 몸 안에서 일어나는 일이라거나 삶의 주기의 자연스러운 과정임을 알지 못한다. 11세 이후에는 형식적 조작기(formal operational period)로 성인들이 생각하는 것과 같은 수준에 도달한다. 인지발달에 근거한 연구자들은 죽음을 단일 개념보다는 몇 가지 하위 개념으로 설명하기 시작하였다(Kane 1979). 특히 Kane(1979) 은 열 가지 하위 개념을 모두 이해할 때 성숙하고 완성된 죽 음 개념에 도달한다고 주장하였다. 대표적인 하위 개념 중 가장 필수적인 것은 비가역성 또는 최종적임은 물리적 육체 의 죽음이 되살아 날 수 없다는 개념으로, 죽은 뒤 형태 유지 여부에 대한 가능성은 열려 있다. 보편성 또는 적용성(applicability)은 모든 생명체가 결과적으로 죽는다는 개념이다. 비기능성(nonfunctionality) 또는 기능정지(cessation)는 생 물이 죽으면 일반적인 신체의 생명 활동(걷기, 먹기, 듣기, 보 기, 학습) 등의 능력을 상실하는 것이다. 인과성은 객관적 원
인에 의해 죽게 된다는 것으로 나이가 들어서 사망하는 것도 포함한다. 인과성은 다른 세 가지 개념과는 별개이며, 연구자 들 사이에 합의된 개념이 아니다(Brent와 Speece 1993). 연 구자에 따라 개인적 사망(personal mortality), 고령(old age), 예측 불가능(unpredictability), 비신체적 연속성(noncorporeal continuation) 등을 하위 개념으로 주장한다(Brent와 Speece 1993).

하위 개념 같은 일반적 영역 발달보다 특별한 영역 개념을 주장하는 경우도 있다. 건강, 질병, 삶의 주기와 같은 생물학 적 현상으로 죽음을 설명하려는 시도도 있다(Carey 1985). 따 라서 소아에게 죽음을 설명할 때 “천국에 가셨단다”라든가 “좋은 곳에서 편히 쉬고 계시단다”라는 완곡한 표현은 훗날 생 물학적 설명을 어렵게 만들 수 있다(Cotton과 Range 1990).

\section{죽음의 하위 개념의 발달학적 이해}

이러한 하위 개념 이론이 전개되면서 몇 가지 궁금증이 생 겨났다(Orbach 등 1987). 첫째, 이러한 하위 개념이 연령대 별 또는 개념별로 발달 순서가 있는가, 둘째, 하위 개념 사이 에 서로 어떻게 영향을 주는가, 셋째, 어떠한 하위 개념을 이 해하고 인식할 때 죽음을 완전히 이해한 것으로 볼 것인가 등이다.

Smilansky(1981)는 이스라엘의 4 10세 소아를 대상으로 죽음에 대한 인식을 조사하였고, 비가역성, 비기능성(기능정 지), 불가피성, 인과성의 순서로 하위 개념을 인식한다고 보고 하였다. Schonfeld와 Smilansky(1989)는 같은 평가 도구를 이용하여 미국의 사회경제적 수준이 낮은 가정의 아이들을 평정하였고, 이스라엘 아이들이 미국 아이들에 비해 비가역 성과 비기능성을 먼저 인지하는 것으로 보고하였다. 상당수 연구에서 인과성이 하위 개념 중 가장 늦게 인지된다고 보고 한 반면, 보편성, 기능정지, 비가역성, 인과성의 순서로 인식 과정이 진행되고 나면 불가피성의 개념이 맨 뒤에 나타난다 는 보고도 있다(Hoffman과 Strauss 1985). 초등학교 1 2학 년생 99명을 대상으로 한 연구에서는 비가역성과 불가피성 을 먼저 인식하고 기능정지와 인과성의 이해가 이어진다고 하였으며, 죽음 개념을 단일 또는 통합 개념으로 이해하기보 다는 하위 개념별로 각각 연구해야 한다고 주장하였다(Lazar와 Torney-Purta 1991). 이제까지의 연구를 토대로 볼 때 발달 단계에 따른 죽음에 대한 이해는 영아기에는 이루어지 지 못하고, 학령 전기에 다양한 조건에서 일시적이고 가역적 인 반응으로 인식하며, 6 8세의 아동에서는 죽음의 비가역 성을 이해하고, 9 12세 이후에는 죽음의 비가역성, 보편성, 비기능성을 이해하며 인과성을 인지하기 시작한다(Dixon 2006). 청소년기에는 죽음의 네 가지 하위 개념에 대하여 모 
Table 1. Chronological development of the subconcepts of death for children

\begin{tabular}{|c|c|c|c|c|}
\hline Stage & \multicolumn{4}{|c|}{ Contents and subconcepts } \\
\hline Infant & \multicolumn{4}{|c|}{ No cognitive understanding } \\
\hline Preschooler & \multicolumn{4}{|c|}{ Temporary, reversible, not me, sleeping or staying under different places } \\
\hline \multirow[b]{2}{*}{ Stage } & \multicolumn{4}{|c|}{ Subconcepts } \\
\hline & Irreversibility & $\begin{array}{l}\text { Universality } \\
\text { (inevitability) }\end{array}$ & $\begin{array}{c}\text { Nonfunctionality } \\
\text { (cessation) }\end{array}$ & Causality \\
\hline \multicolumn{5}{|l|}{ After preschooler } \\
\hline \multicolumn{5}{|l|}{ School ages } \\
\hline 6-8 years & $\vee$ & & & \\
\hline $9-12$ years & $\vee$ & $\vee$ & $\vee$ & Not typical \\
\hline Adolescents & $\vee$ & $\vee$ & $\vee$ & $\vee$ \\
\hline
\end{tabular}

두 인지하게 된다(Table 1).

\section{소아의 죽음 인식에 영향을 미치는 요인들}

Smilansky(1981)의 연구에서는 아동이 어린 경우 큰 아동 에 비해 동물보다 사람의 죽음을 좀 더 정확하게 이해하였으 나, Hoffman과 Strauss(1985)의 연구는 대상에 따른 차이를 발견하지 못하였다. 같은 평가 도구를 사용하더라도 연구자 에 따라 하위 개념의 인식 순서가 다르게 나타났으며, 대상이 사람인 경우와 동물인 경우도 다른 결과를 보였다(Orbach 등 1987). 사람을 대상으로 한 경우 인과성에 이어 최종적임, 보편성, 비가역성, 고령의 순서였으나, 동물의 죽음에 대해서 는 인과성, 고령, 최종적임, 보편성, 불가피성으로 차이가 있 었다. Lazar와 Torney-Purta(1991)는 아이들이 사람보다 동 물의 죽음을 더 먼저 이해할 것으로 기대하였으나, 실제로는 인간의 죽음을 더 정확하게 이해하였다. 단, 기능정지 개념 은 동물에서 더 먼저 정확하게 이해하였다. 이에 대해 저자들 은 아이들이 동물의 사체를 목격할 기회가 더 많았을 것이고, 그에 따라 사체경직 등 비기능성을 확인하였기 때문일 것으 로 설명하였다.

소아가 죽음의 하위 개념을 인식하는 시기나 순서는 개인 의 경험이나 특성에 따라 달라질 수 있으며, 소아의 연령, 인 지발달, 죽음의 노출 등에 비해 종교(Cuddy-Casey와 Orvaschel 1997)나 사회문화적 영향은 비교적 덜 받는 것으로 알 려져 있다(Slaughter 2005). 그러나 최근 연구에서는 차이가 관찰되었다. 세 부류의 4 7세 아동, 즉 런던 거주 백인 가정, 런던 거주 회교도 가정, 파키스탄 시골 거주 회교도 가정 자 녀들을 비교한 결과, 비가역성, 비기능성, 불가피성, 인과성의 순서는 집단별 차이가 없었으나, 파키스탄에 거주하는 아동 은 비가역성 개념을 먼저 인식하였다. 국가별 문화적 차이는 없었으나, 도시지역과 농촌지역의 차이는 있음을 시사하였 다(Panagiotaki 등 2015). 40명의 한국 아동들에게 서부 유럽
과 동아시아의 죽음 관련 그림책을 보여 주고 죽음의 하위요 인에 대해 평가한 결과, 유럽 문헌에서는 인과성과 비기능성 이 초자연성(supernatural aspect)과 결합되어 나타난 반면, 아시아 문헌에서는 죽음의 인과성에 초점을 맞추고 자연경 과로 설명하는 차이가 있다고 하였다(Lee 등 2014). 6학년 아 동을 대상으로 한 중국의 연구에서는 성별, 건강상태, 종교, 장례식 참석 경험, 친척이나 애완동물의 죽음 경험 등이 현재 의 죽음 인식에 유의한 영향이 없다고 하였다(Yang과 Chen 2002).

소아의 죽음 연구는 대개 건강한 아동들을 대상으로 하였 으므로, 상황이나 환경적 특성에 따른 차이를 규명하기 위해 서는 각각의 사례와 상황에 대한 분석이 필요하다. 몇몇 만 성 신체질환 아동이나 자살시도 아동들을 대상으로 한 연구 에서는 죽음 개념에 대한 왜곡과 덜 성숙한 개념을 갖고 있었 다(Cuddy-Casey와 Orvaschel 1997). 만성질환을 않고 있는 아동은 자신의 경험을 통해 죽음의 의학적 또는 생물학적 영 역 중 비가역성, 기능정지 또는 인과성에 대한 이해가 촉진될 수 있다(Slaughter 2005). 이러한 왜곡 때문에 죽음에 대해 좀 더 매력을 느끼기도 하고, 자살시도 아동들은 죽음의 영속 성을 덜 느끼는 것처럼 보인다. 부모가 자살이나 타살로 사 망한 경우 역시 자녀의 발달에 심각한 영향을 미칠 것이다 (Davis 2010), 부모 중 어느 한쪽이 사망한 후 남은 부모가 죽 은 이를 비난하거나 자녀가 죽은 부모 이야기하는 것을 금지 한다든가 하는 것은 아동의 죽음 개념에 바람직하지 않은 영향을 미칠 수 있다.

\section{부모의 죽음을 경험한 소아의 우울 및 불안장애}

부모의 죽음을 경험한 소아의 애도반응은 정상 과정이라 할지라도 불안, 우울 등 정서적 문제를 가중시킨다(Davis 2010). 소아기에 부모의 죽음을 경험하는 것은 항상 아동에게 큰 상 처를 준다. 만 18 세 이전에 죽음을 경험하는 경우는 대략 $5 \%$ 
정도이다(Parsons 2011). 부모의 죽음은 아동의 애도과정에 서 다양한 부정적 결과를 유발할 수 있다. 약물 남용의 가능 성 증가(Sweeting 등 1998), 우울증 가능성 증가(Harrison 등 2001), 학업 성취도 저하(Abdelnoor와 Hollinsb 2004; Fauth 등 2009), 성인기 취업률 저하(Parsons 2011), 범죄 행동 증가 (Liddle과 Solanki 2002) 등이다. 부모의 죽음 이후 아동이 겪는 경험은 다양한 요소와 위험요인에 따라 달라진다. 이전 의 상실과 관련된 경험이나 적응 스타일 등 아동과 관련된 요인도 있으며, 사망한 가족과의 관계나 사회적 관계와 관련 된 요인이 있고, 더 넓게는 죽음 당시의 상황이나 문화와 관 련된 요인도 영향을 준다(Ribbens McCarthy와 Jessop 2005). 소아기에 한쪽 부모가 사망하게 되는 경우 다른 부모의 상 징적 또는 일시적 상실을 동시에 경험(double jeopardy)하게 된다(Riches와 Dawson 2000). 배우자가 사망한 경우 한쪽 부모도 상실감과 우울, 정서적 고통과 애도를 경험하고 이런 시기에 아동을 잘 돌보기 힘들기 때문이다. 부모가 자녀를 돌 보는 것에 일시적인 변화가 있어도 아동은 스트레스를 경험 한다. 이러한 영향들이 복합되어 부모의 죽음은 아동의 우울, 불안, 죄책감, 불안정성의 위험성을 높인다. 환경적, 경제적 변화 역시 동반될 수 있어 부모의 죽음은 소아기 발달과정에 서 정신건강의 위기를 포함한 다양한 어려움을 야기시킬 수 있다. 부모의 사망 이후 소아의 우울증과 불안장애의 위험이 증가한다는 것은 다양한 연구를 통해 일관되게 보고되고 있 다. 부모가 갑자기 사망한 경우 아동청소년기 우울증의 위험 이 약 3 배 증가하고, 외상 후 스트레스장애의 발생 위험성 역 시 증가한다(Melhem 등 2008). 특히 어머니가 사망한 경우, 남을 비난하게 되는 상황이거나 자존감이 낮을 경우, 대응 방식이 부정적이고 복합애도 상황일 경우, 부모가 사망한지 2년이 경과한 후에도 우울증은 증가하였다(Brent 등 2009). 청 소년기보다 학령 전기에 부모 사망을 경험한 경우, 자살이나 사고, 타살과 같은 외부적인 요인으로 부모가 사망한 경우, 아동의 정신건강 문제 위험은 더욱 증가한다(Berg 등 2016). 우울증과 불안장애 이외에도 아동청소년 시기의 부모 사망 은 초기 청년기의 자해로 인한 입원 위험성을 높인다(Rostila 등 2016). 특히 자연경과적인 사망이 아니라 외부적 이유로 인한 사망이며, 부모 사망을 경험할 당시 아동의 연령이 어린 경우 자해의 위험성이 더욱 증가하였다.

자해 행동 이외에도 부모의 죽음은 아동청소년의 자살 위 험성을 높인다. 북유럽에서 25년간 진행된 장기추적연구에 서 어린 시절 부모의 사망을 경험한 아동청소년의 $0.14 \%$ 가 자살로 사망하였고, 부모의 사망을 경험하지 않은 경우에는 $0.07 \%$ 가 자살로 사망하여 상대위험도가 2.02[95\% confidence interval(CI), 1.75 2.34]였다(Guldin 등 2015), 특히 부
모가 자살로 사망한 경우의 상대위험도는 3.44(95\% CI, 2.61 4.52)로, 자살 이외의 원인으로 사망한 경우인 $1.76(95 \% \mathrm{CI}$, 1.49 2.09)보다 높았다. 부모의 죽음은 자녀의 알코올 남용 과 의존의 위험성도 증가시켰다(Hamdan 등 2013). 부모가 사망한 후 5 년 동안 추적 관찰한 결과 알코올 남용과 의존의 위험이 2.44배 증가하였다. 특히 13세 이상이었을 경우, 파탄 적 행동장애가 있을 경우, 기능 저하가 심할 경우 알코올 문제 는 더욱 증가하였다. 아동이 직접 사별을 경험하지 않더라도 아동의 애도와 관련해서 간접적인 상황도 영향을 미친다. 어 머니가 애도시기에 있을 경우 자녀의 심리 상태에 영향을 미 칠 수 있다. 어머니가 가까운 가족의 사별을 경험할 때, 애도 반응으로 불안정한 심리 상태가 지속될 경우 자녀의 정신병 적 증상(psychosis)의 위험성이 증가한다(Abel 등 2014). 이 는 단순한 가족력으로만 설명이 되지 않았고 대가족보다는 핵 가족일 경우, 나이가 어릴 때 경험한 경우, 자살로 사망한 경 우 증상 발생의 위험성이 더 컸다.

형제가 사망하였을 때도 아동의 우울증 발생 위험은 증가 한다. 형제가 사망하기 이전의 다양한 정신건강 문제를 보정 하더라도 물질 남용을 비롯한 정신건강 질환의 위험도가 증 가하였다(Bolton 등 2016). 특히 13세 이하에서 경험하였을 경우 우울증 발생 비율이 7배가량 증가하였다. 형제를 잃은 직접적인 슬픔과 더불어 자식을 잃은 부모의 애도 상태가 영 향을 끼치기 때문이다. 또한 정신건강 문제뿐만이 아니라 두 통, 복통과 같이 신체적 증상으로 병원을 방문하는 횟수가 현 저히 증가하였다. 부모의 사망 후 이사를 하거나 가족이나 친 구들과 분리되어 지내는 것은 더욱 많은 스트레스를 주었고 적응을 어렵게 만든다(Mahon 1999; Thompson 등 1998).

아동청소년기의 부모의 사망은 아동청소년기의 정신건강에 만 국한되지 않고 성인기까지 영향을 미친다(Ellis 등 2013). 일상생활에서의 변화가 크고 돌봄이 지속되지 않을 경우, 애 도를 다루기 어렵고 성인기에 외로움, 불안정감을 더 많이 느끼게 된다. 성인이 되면 우울증의 위험성은 증가하며, 특 히 어머니가 사망하거나, 부모의 사망 이유가 자살이나 타 살, 사고 등으로 사망한 경우, 연령이 어린 경우 성인기의 우 울증 발생 위험과 정신건강 위험성이 더욱 증가하였다(Ellis 등 2013). 정신건강뿐만 아니라 중년기의 전반적인 안녕이 나 신체건강에도 부정적 영향을 미친다(Maier와 Lachman 2000). 따라서 소아청소년이 부모의 죽음을 경험한 경우 애 도과정을 잘 극복하고 정신건강의 위험을 예방하기 위한 각 별한 관심과 도움이 필요하다.

\section{소아가 죽음을 잘 이해하도록 돕는 방법}

소아청소년의 죽음에 대한 이해를 도와야 할 상황은 가족 
이 사망했을 때, 본인의 죽음을 앞두고 있을 때, 자살예방교 육의 일환 등 세 가지가 있다(Gilbert 1996). 첫째, 부모나 형 제, 자매가 사망하였을 때 소아청소년이 그것을 극복하는 과 정은 죽음에 대한 인지(recognition), 충분한 애도를 통한 재 조직화(reorganization), 과거에 얽매이지 않고 앞으로 나아 가는 재투자(reinvestment)의 단계를 거친다. 먼저, 소아청 소년이 죽음을 제대로 인지하는 것이 극복으로 나아가기 위 한 선행 조건이 되는데, 인지를 잘 할 수 있도록 하기 위해서 는 아동이 이해할 수 있는 언어로 죽음과 그 원인을 설명하는 것이 필요하다. 죽음을 완곡하게 돌려 말하거나, 은유적으로 표현하는 것은 오히려 불필요한 환상이나 믿음을 불러일으 킬 뿐이고 충분한 애도를 통한 해결에 방해가 될 뿐이다 (Mitchell 등 2006). 둘째, 재조직화의 과정은 상실에 대한 충분한 애도를 통하여 가능해진다. 그러기 위해서는 사망한 사람에 대한 아동의 기억이나 감정을 충분히 표현하도록 격 려해야 한다. 셋째, 재투자의 단계는 마침내 망인을 마음에 서 떠나 보내고 상실의 충격이 해결되고 앞으로 나아가는 것 이다. 이때, 애도반응이 6개월 이상으로 너무 길어지거나 정 도가 심하거나 생활이나 관계 기능이 심각하게 떨어지면 전 문가와 상의를 하는 것이 좋다.

연령별로 소아청소년의 죽음의 이해를 증진하기 위한 요 령은 다음과 같다(Slaughter 2005). 3세 이하의 영유아는 죽 음을 이해시킬 수 있는 인지적 능력을 가지고 있지 않음은 물 론(Piaget 1960), 아직 분리-개별화 과정을 완성하지 못하였 기 때문에 대상에 대한 표상 자체가 내재화되어 있지 않기도 하다(Coates 2004). 그래서 죽음을 이해시키려고 노력하기 보다는 부정적 영향을 덜 받고 잘 발달하도록 도와주는 것이 중요하다. 가능한 양육자가 바뀌지 않고 낮익은 환경에서 가 급적 애착 대상자가 바뀌지 않고 일관성 있는 양육을 제공하 는 것이 좋다. 그럼으로써 이 시기의 주요 과제인 소수의 양 육자에게 애착관계의 위계를 형성하고 애착관계를 기반으 로 한 긍정적 대인관계의 내적 작동 모형(internal working model)이 완성되도록 관심을 기울여야 한다(Bowlby 1969). 사망한 가족이 애착 대상인 경우는 저항(protest), 절망(despair), 애착분리(detachment)의 과정을 거쳐 애착관계의 붕 괴를 경험하게 되므로(Bowlby 1951), 새로운 애착 대상과의 안정적 관계를 맺을 수 있도록 그 취약성을 특별히 고려해 야 한다. 학령 전기 아동은 인지적으로 미성숙하므로 애완동 물이나 관상용 식물의 죽음을 경험했던 아이라면 그런 경험 과 현재의 경험을 연결 지어 설명해 주는 것이 좋은 방법이 다(Mitchell 등 2006). 가족 사망의 원인을 아동 자신의 잘못 으로 오해하는 마술적 사고를 할 수 있는 시기이므로 그런 것 이 아니라고 안심시켜야 할 때가 있다. 죽음이나 이별과 관련
된 동화나 그림책을 같이 보며 망자에 대한 감정을 표현하 는 것도 도움이 된다. 학령기 아동은 죽음을 제대로 이해할 수 있는 나이이므로 사망의 원인에 대해서도 솔직하고 구체 적으로 설명하여야 한다. 아동 자신의 감정을 말로 충분히 표현할 수 있도록 격려한다. 청소년기는 어른과 유사한 감정 반응을 보이는 시기이다. 가족 대신 친구와 함께 있고 싶어 할 수도 있다. 특히 사랑하는 사람과 같이 있기 위하여 자살 에 대한 생각을 할 수도 있으므로 유의하여야 한다.

소아가 장례식에 참석할 것인가에 대해서는 대체로 긍정 적이다(Ginsberg 2015). 죽음에 대한 불필요한 환상을 갖지 않게 해주고, 가족 행사에 참여함으로써 가족의 중요한 구성 원이라고 생각하게 하는 효과가 있다. 죽은 가족을 기리는 사람들을 보면서 망자에 대한 소중함과 자부심을 경험할 수 도 있어 참석의 자율권을 허용하는 것이 필요하다. 단, 어린 아동의 경우 장례식 때 혼자 방치되지 않도록 배려하는 것이 중요하다. 또한, 어른들은 애도반응의 본보기가 되어 주어야 한다(Pruitt 1998). 보호자는 가급적 평소대로 행동하도록 하 고, 아이들과 대화하기 전에 어른 자신이 느끼는 슬픔이나 상실감에 대해 스스로 인식하여야 한다. 아동에게 질문을 할 수 있는 기회를 주고 아동이 가진 두려움이나 공상에 대해서 도 알아본다. 특히 상실이나 외상에 대한 충격을 해결하지 못 한 상태에서 어른 자신이 어린 아동의 일차 양육자가 되는 경우, 아동은 안정적 애착 대신 혼란된 애착을 형성하게 되 어 여러 정신병리에 취약해진다(Bowlby 1969). 즉, 위안을 제공해야 할 당사자가 아동에게 두려움을 주거나 자신이 공 포에 압도된 반응을 보이게 되면, 아동도 애착 체계를 조직 화하지 못하고 상반되거나 모순된 애착행동을 나타내게 되 는 것이다. 한편, 가족의 죽음 중 자살로 인한 경우에는 그 특수성으로 인한 사회적 고립과 낙인감 극복의 부담이 부가 되어 문제가 더 많이 생길 수 있다(Pfeffer 등 1997). 즉각적 불안 반응으로 분노, 수치심, 죄책감의 혼란된 감정을 경험 할 수 있다. 부모가 자살한 경우 남겨진 아이들의 자살 문제 도 다루어져야 한다. 따라서, 그들의 정신병리와 사회 부적응 을 조기에 발견하여 다루어 주는 것이 장기적 부적응으로 이 어질 위험을 줄이는 데 필요하다.

다음으로 소아 본인의 죽음을 앞둔 경우이다(Downing 등 2015). 말기 소아암, 진행성 신경계 질환, 선천성 기형으로 인 해 투병 중일 때가 이에 해당한다. 가장 중요한 것은 부모의 정서적 안정을 도와 부모가 아이에게 충분히 애정을 표현할 수 있도록 함으로써 아동이 안정되고 편안하게 하는 것이다 (Spinetta 1974). 연령별로 살펴 보면, 학령 전기 아동이 질병 을 본인의 나쁜 행위에 대한 처벌로 받아들인다면 그게 아 니라는 것을 알게 해주고, 죽어가는 아동의 생의 존엄과 질 
을 유지하도록 돕는 것, 아동의 소원과 죽음에 대한 계획을 표현하도록 돕는 것이 필요하다. 학령기 아동은 죽음을 더 잘 이해하고 아픔과 괴로움을 더 두려워하는 것이 특징이다. 자신의 예후에 대한 결정권을 갖고 싶어하며, 특히 10 세 이 후에는 상대방의 입장을 고려하는 능력이 발달하면서 고통 이 커지게 된다. 질병에 대해 본인에게 알리고 걱정에 관하 여서 대화하는 것이 좋다. 청소년기는 사생활과 자존심을 존 중해주고 친구를 만나게 해주는 것이 필요하다. 가족과 형제 를 보호하길 원하기 때문에 자신의 감정을 감추는 경우가 많은데 분노, 슬픔, 두려움, 소외감, 죄의식을 표현하도록 격 려하는 것이 좋다.

마지막으로 자살예방의 일환으로서 청소년에게 죽음을 이해하고 준비하는 교육을 해야 할 때가 있다(Ro 2010). 제 1 단계로서 죽음의 의미에 대한 교육은 청소년기의 특징인 개 인적 우화 등을 극복하고 죽음에 대한 태도의 전환을 가져 오기 위함이다. 제 2 단계는 죽음의 과정에 대한 교육으로 죽 음에 직면한 사람들의 심리 상태와 단계, 국면을 이해하여 죽 음을 맞이하는 사람들에게 도움을 줄 수 있게 하고 본인의 죽음을 준비할 수 있는 대처방식에 대한 정보를 제공한다. 제3단계인 죽어감의 또 다른 형태에 대한 교육은 자살, 비행 을 저지르는 학생의 심리 상태에 대한 이해와 그에 대한 자 신의 의견을 자연스럽게 이야기함으로써 대처방안까지 청소 년 스스로 탐색하는 과정이다. 제4단계로 삶의 의미에 대한 교육은 생명의 존중감을 다루고 가정과 학교, 그리고 지역사 회에 자신이 공동체의 일원임을 깨달을 수 있는 체험활동을 하며, 자신에게 유서를 작성하는 활동을 통하여 자신이 지나 온 인생을 되돌아보고 새로운 삶의 목적과 가치관을 점검하 고 발전시켜 자아 존중감을 확립시키도록 하는 것이다.

\section{결 론}

죽음은 아동에게 어떤 영향을 미칠 것인가? 죽음은 인간 뿐 아니라 모든 생물에게 일어나는 자연 현상이고, 당연한 삶의 귀결임에도 불구하고 죽음의 개념을 이해하고 받아들 이는 것은 쉽지 않다. 살면서 깨우쳐야 하는 사회화 과정이라 고 생각하지만 아동이 죽음이라는 개념을 터득해 가는 과정 과 소아기에 경험하는 죽음과 관련된 정서 반응을 탐색할 필 요가 있다. 사회문화적, 인종적, 성별 변수와 상관없이 아동 은 죽음의 속성 중 비가역성 및 비기능성을 깨우치고, 불가피 성과 인과성을 순차적으로 알게 된다. 그 정도나 시기는 아 동의 인지발달 경과와 관련 있다. 죽음의 대상이 부모나 가족 인 경우는 정서 반응이 더욱 강렬할 수 있다. 가족 구성원의 상실 후 우울 및 불안 반응이 나타날 수 있으며, 적절히 해결
되지 못할 경우 급성 또는 만성 장애로 진행된다. 아동이 가 족 구성원의 사망을 경험하였을 때는 아동의 발달 상태를 고려한 적합한 언어와 방법을 통하여 사실을 제대로 인지하 도록 도움으로써, 충분한 애도를 통하여 상실을 극복하고 삶 에 다시 적응할 수 있도록 돕는 것이 필요하다. 특히 가족 구 성원의 사망원인이 자살인 경우 아동의 분노, 수치심, 죄책감 을 다루어줌으로써 정신병리와 사회 부적응의 예방이 중요 하고, 남겨진 아동의 자살 문제도 고려하여야 한다. 이상과 같이 소아가 죽음에 대해 느끼는 하위 감정은 발달 순서, 연 구 방법, 죽음의 대상, 연령, 인지발달, 개인 성향 등에 따라 일관된 모습이 아닐 수 있으므로 각각의 요인에 대해 평가 할 필요가 있으며, 치료가 필요하다면 역시 복합적 요인을 분석하여 치료에 반영하여야 한다.

\section{Acknowledgments}

The theme of this article was presented at the Spring meeting of the Korean Academy of Child and Adolescent Psychiatry on 13th May, 2016, Seoul, Korea.

This work was supported by a grant from the Korea Mental Health Technology R \& D Project (HM15C1084).

\section{Conflicts of Interest}

The authors have no financial conflicts of interest.

\section{REFERENCES}

Abdelnoor A, Hollinsb S. The effect of childhood bereavement on secondary school performance. Educ Psychol Pract 2004;20:43-54.

Abel KM, Heuvelman HP, Jörgensen L, Magnusson C, Wicks S, Susser E, et al. Severe bereavement stress during the prenatal and childhood periods and risk of psychosis in later life: population based cohort study. BMJ 2014;348:f7679.

Berg L, Rostila M, Hjern A. Parental death during childhood and depression in young adults - a national cohort study. J Child Psychol Psychiatry 2016 Apr 5 [Epub]. http://dx.doi.org/10.1111/jcpp.12560.

Bolton JM, Au W, Chateau D, Walld R, Leslie WD, Enns J, et al. Bereavement after sibling death: a population-based longitudinal casecontrol study. World Psychiatry 2016;15:59-66.

Bowlby J. Attachment and loss, vol. 1: attachment. New York: Basic Books; 1969.

Bowlby J. Maternal care and mental health. Bull World Health Organ 1951;3:355-533.

Brent D, Melhem N, Donohoe MB, Walker M. The incidence and course of depression in bereaved youth 21 months after the loss of a parent to suicide, accident, or sudden natural death. Am J Psychiatry 2009; $166: 786-794$

Brent SB, Speece MW. 'Adult' conceptualization of irreversibility: implications for the development of the concept of death. Death Stud 1993;17:203-224.

Bromberg W, Schilder P. Death and dying. Psychoanal Rev 1933;20: 133-185.

Carey S. Conceptual change in childhood. Cambridge, MA: MIT Press; 1985.

Childers P, Wimmer M. The concept of death in early childhood. Child Dev 1971:42:1299-1301.

Coates SW. John Bowlby and Margaret s. Mahler: their lives and theories. J Am Psychoanal Assoc 2004;52:571-601. 
Cotton CR, Range LM. Children's death concepts: relationship to cognitive functioning, age, experience with death, fear of death, and hopelessness. J Clin Child Psychol 1990;19:123-127.

Cuddy-Casey M, Orvaschel H. Children's understanding of death in relation to child suicidality and homicidality. Clin Psychol Rev 1997; 17:33-45.

Davis D. Child development: a practitioner's guide. 3rd ed. New York: Guilford Press;2010.

Dixon SD. Understanding children: theories, concepts and insights. In: Dixon SD, Stein MT. Encounters with children: pediatric behavior and development. 4th ed. Philadelphia, PA: Mosby;2006. p.12-43.

Downing J, Knapp C, Muckaden MA, Fowler-Kerry S, Marston J; ICPCN Scientific Committee. Priorities for global research into children's palliative care: results of an International Delphi Study. BMC Palliat Care 2015;14:36.

Ellis J, Dowrick C, Lloyd-Williams M. The long-term impact of early parental death: lessons from a narrative study. J R Soc Med 2013; 106:57-67.

Fauth B, Thompson, M, Penny A. Associations between childhood bereavement and children's background, experiences and outcomes: secondary analysis of the 2004 mental health of children and young people in Great Britain data. London: National Children's Bureau; 2009.

Freud A. Infants without families: the writings of Anna Freud, Vol III. New York: International Universities Press;1973. [Writings from 1939 to 1945].

Fulton R, Klass D, Doka KJ, Kastenbaum B. Introduction to special issue: Robert Jay Kastenbaum (1932-2013). Omega (Westport) 20142015;70:3-11.

Gaab EM, Owens GR, MacLeod RD. Caregivers' estimations of their children's perceptions of death as a biological concept. Death Stud 2013;37:693-703.

Gay P. Freud: a life for our time. New York: W. W. Norton;2006. p.390403.

Gilbert KR. "We've had the same loss, why don't we have the same grief?" Loss and differential grief in families. Death Stud 1996;20: 269-283.

Ginsberg KR. Building resilience in children and teens: giving kids roots and wings, 3rd Ed. Elk Grove Village, IL: American Academy of Pediatrics;2015.

Guldin MB, Li J, Pedersen HS, Obel C, Agerbo E, Gissler M, et al. Incidence of suicide among persons who had a parent who died during their childhood: a population-based cohort study. JAMA Psychiatry 2015;72:1227-1234.

Hamdan S, Melhem NM, Porta G, Song MS, Brent DA. Alcohol and substance abuse in parentally bereaved youth. J Clin Psychiatry 2013; $74: 828-833$.

Han DH, Lee JJ, Moon DS, Cha MJ, Kim MA, Min S, et al. Korean version of inventory of complicated grief scale: psychometric properties in Korean adolescents. J Korean Med Sci 2016;31:114-119.

Harrison L, Harrington R. Adolescents' bereavement experiences. Prevalence, association with depressive symptoms, and use of services. J Adolesc 2001;24:159-169.

Hoffman SI, Strauss S. The development of children's concepts of death. Death Stud 1985;9,469-482.

Jeon HJ, Bae J, Woo JM. Recent statistics and risk factors of suicide in children and adolescents. J Korean Med Assoc 2013;56:93-99.

Kane B. Children's concept of death. J Genet Psychol 1979;134:141-153.

Lazar A, Torney-Purta J. The development of the subconcepts of death in young children: a short-term longitudinal study. Child Dev 1991; 62:1321-1333.

Lee JS, Kim EY, Choi Y, Koo JH. Cultural variances in composition of biological and supernatural concepts of death: a content analysis of children's literature. Death Stud 2014;38:538-545.
Liddle M, Solanki AR. Persistent young offenders: research on individual backgrounds and life experiences. London: NACRO;2002.

Mahon MM. Secondary losses in bereaved children when both parents have died: a case study. Omega 1999;39:297-314.

Maier EH, Lachman ME. Consequences of early parental loss and separation for health and well-being in midlife. Int J Behav Dev 2000; 24:183-189.

Melhem NM, Walker M, Moritz G, Brent DA. Antecedents and sequelae of sudden parental death in offspring and surviving caregivers. Arch Pediatr Adolesc Med 2008;162:403-410.

Mitchell AM, Wesner S, Brownson L, Gale DD, Garand L, Havill A. Effective communication with bereaved child survivors of suicide. J Child Adolesc Psychiatr Nurs 2006;19:130-136.

Nagy M. The child's theories concerning death. J Genet Psychol 1948; 73:3-27.

Orbach I, Talmon O, Kedem P, Har-Even D. Sequential patterns of five subconcepts of human and animal death in children. J Am Acad Child Adolesc Psychiatry 1987;26:578-582.

Panagiotaki G, Nobes G, Ashraf A, Aubby H. British and Pakistani children's understanding of death: cultural and developmental influences. Br J Dev Psychol 2015;33:31-44.

Parsons S. Long-term impact of childhood bereavement: preliminary analysis of the 1970 British Cohort Study (BCS70). CWRC Working Paper. London: Childhood Wellbeing Research Centre;2011.

Perrin EC, Gerrity PS. There's a demon in your belly: children's understanding of illness. Pediatrics 1981;67:841-849.

Pfeffer CR, Martins P, Mann J, Sunkenberg M, Ice A, Damore JP Jr, et al. Child survivors of suicide: psychosocial characteristics. J Am Acad Child Adolesc Psychiatry 1997;36:65-74.

Piaget J. The child's conception of the world. Paterson, NJ: Littlefleld, Adams; 1960

Pruitt DB. Your child: what every parent needs to know about childhood development from birth to preadolescence. New York: HarperCollins; 1998 .

Ribbens McCarthy J, Jessop J. Young people, bereavement and loss: disruptive transitions? London: Joseph Rowntree Foundation/National Children's Bureau;2005.

Riches G, Dawson P. An intimate loneliness: supporting bereaved parents and siblings. Buckingham: Open University Press;2000.

Ro SW. A study on the adolescent suicides and "death-preparing education". J Educ Develop 2010;26:5-26.

Rostila M, Berg L, Arat A, Vinnerljung B, Hjern A. Parental death in childhood and self-inflicted injuries in young adults-a national cohort study from Sweden. Eur Child Adolesc Psychiatry 2016 Mar 1 [Epub]. http://dx.doi.org/10.1007/s00787-016-0833-6.

Rousseau C, Jamil U, Bhui K, Boudjarane M. Consequences of 9/11 and the war on terror on children's and young adult's mental health: a systematic review of the past 10 years. Clin Child Psychol Psychiatry 2015;20:173-193.

Schilder P, Wechsler D. The attitudes of children toward death. J Genet Psychol 1934;45:406-451.

Schonfeld DJ, Smilansky S. A cross-cultural comparison of Israeli and American children's death concepts. Death Stud 1989;13:593-604.

Shneidman ES. On the nature of suicide. San Francisco: Jossey-Bass; 1969.

Slaughter V. Young children's understanding of death. Aust Psychol 2005;40:179-186.

Smilansky S. Different mourning patterns and the orphan's utilization of his intellectual ability to understand the concept of death. Adv Thanatol 1981;5:39-55.

Spinetta JJ. The dying child's awareness of death: a review. Psychol Bull 1974;81:256-260.

Sweeting H, West P, Richards M. Teenage family life, lifestyles and life chances: associations with family structure, conflict with parents and 
joint family activity. Int J Law Policy Family 1998;12:15-46.

Terr LC. Childhood traumas: an outline and overview. Am J Psychiatry 1991;148:10-20.

Thompson MP, Kaslow NJ, Price AW, Williams K, Kingree JB. Role of secondary stressors in the parental death-child distress relation. J
Abnorm Child Psychol 1998;26:357-366.

White EA, Elsom B, Prawat R. Children's conceptions of death. Child Dev 1978;49:307-310.

Yang SC, Chen SF. A phenomenographic approach to the meaning of death: a Chinese perspective. Death Stud 2002;26:143-175. 